\title{
台湾东部黑潮与邻近东海水中的钡及其 对黑潮水入侵的指示
}

刘伟 $1,2,3$, 宋金明 $1,2,4^{*}$, 袁华茂 ${ }^{1,2,4}$, 李宁 ${ }^{1,2,4}$, 李学刚 $1,2,4$, 段丽琴 $1,2,4$

1. 中国科学院海洋生态与环境科学重点实验室, 中国科学院海洋研究所, 青岛 266071;

2. 中国科学院大学, 北京 100049 ;

3. 山东省分析测试中心, 济南 250014;

4. 青岛海洋科学与技术国家实验室海洋生态与环境科学功能实验室, 青岛 266237

*通讯作者, E-mail: jmsong@qdio.ac.cn

收稿日期: 2017-02-06; 接受日期: 2017-03-22; 网络版发表日期: 2017-05-10

中国科学院创新先导专项项目(编号: XDA11020102)、青岛海洋科学与技术国家实验室“鳌山人才”计划项目(编号: 2015ASTP-OS13)与鳌 山科技创新计划项目深海专项项目(预研)(编号: 2016ASKJ14)和山东省-国家基金委联合基金项目(编号: U1606404)资助

摘要通过对台湾以东黑潮主流径及邻近东海海域2014年5 6月期间的调查, 研究了海水中溶解钡(Ba)的地 球化学分布特征, 评估了黑潮对东海海水 $\mathrm{Ba}$ 的影响和输入通量, 将 $\mathrm{Ba}$ 作为指示指标定量刻画了黑潮入侵东海的 范围与程度. 黑潮主流径各站位海水中溶解Ba垂直分布上从表层至深层浓度逐渐增高, 浓度范围为4.91 19.2 $\mu \mathrm{g}$ $\mathrm{L}^{-1}$. 东海海域表层海水 $\mathrm{Ba}$ 浓度分布以近岸海域为最高, 向外海逐渐降低; 底层则出现近岸和外侧海域Ba浓度高, 陆架中间海域Ba浓度低的现象.水交换模型估算得出黑潮水在 $5 \sim 10$ 月间向东海的Ba输入通量共计为 $2.19 \times 10^{8} \mathrm{~kg}$, 并以次表层水的输入通量为最大. 调查海域 $\mathrm{Ba}$ 的分布特征指示黑潮在台湾东北部海域涌升, 台湾海峡北向出水 抑制黑潮表层水向东海陆架入侵, 黑潮次表层水从陆架底层外侧逐渐影响东海. 以溶解钡(Ba)作为端元估算参 数计算得出, 在调查期间, 黑潮表层水对东海陆架区域影响不大, 黑潮次表层水沿陆架底层向上爬升, 从台湾东 北海域沿陆架中部向西北方向侵入, 形成一支黑潮入侵流, 至钱塘江口附近黑潮水占比仍可达到 $65 \%$ 左右. 东 海陆架底层外侧大部被黑潮水所控制, $100 \mathrm{~m}$ 等深线以深处黑潮水能够占 $95 \%$ 以上的比例. 在台湾东北部DH9断 面, 黑潮次表层水从陆架坡折处沿底部向西侵入, 黑潮水占比 $95 \%$ 的位置可达 $122^{\circ} \mathrm{E}$ 左右, 垂直向上黑潮水所占 比例越小. 海水溶解 $\mathrm{Ba}$ 可以细致地刻画黑潮入侵东海的情景, 其地球化学特性使其成为指示黑潮入侵东海的有 效指标, 为定量揭示黑潮与东海的相互作用提供了新的手段.

关键词＼cjkstart溶解钡, 指示指标, 地球化学特征, 黑潮入侵, 东海陆架

中文引用格式: 刘伟, 宋金明, 袁华茂, 李宁, 李学刚, 段丽琴. 2017. 台湾东部黑潮与邻近东海水中的钡及其对黑潮水入侵的指示. 中国科学: 地球科学, 47: 972-984, doi: 10.1360/N072016-00338

英文引用格式： Liu W, Song J M, Yuan H M, Li N, Li X G, Duan L Q. 2017. Dissolved barium as a tracer of Kuroshio incursion in the Kuroshio region east of Taiwan Island and the adjacent East China Sea. Science China Earth Sciences, 60: 1356-1367, doi: 10.1007/s11430-016-9039-7 


\section{1 引言}

钡(Ba) 是海水中一种重要的微量元素, 其溶解态 在海水中以 $\mathrm{Ba}^{2+}$ 的形式存在, 在海洋垂直分布上属于 深层出现极大值型的微量元素(Bruland, 1983). Ba的 再生主要发生在跃层以深水体, 它作为硅藻等生物 的外壳的构成成分一起输送到深层水中, 而后在深海 中溶解或者降解, 通常会导致深层海水中的高 $\mathrm{Ba}$ 浓 度(Dehairs等, 1980; Paytan和Griffith, 2007; Cardinal等, 2005). 但 Ba在海水中的溶解和沉淀与生物生理作用 的关系不大(Ganeshram等, 2003; Cao等, 2016), 其较保 守的特性使水的交换对其分布影响更为重要, 近年来 被用来作为海水混合的指示指标. Falkner等(1994)、 Roeske等(2012)等利用 Ba作为指示指标研究了北冰洋 海域大西洋水、陆源冰融水等水团的混合. 在南极洲 威德尔海 $\mathrm{Ba}$ 的分布显示出了该海域威德尔环流状况 (Hoppema等, 2010). Nozaki等(2001)和Lin等(2010)的 研究分别指出 $\mathrm{Ba}$ 可以用来指示河流和海底地下水的 排放入海. 因此, 海水中的 $\mathrm{Ba}$ 作为海洋学示踪水团混 合的新型指标所揭示的重要海洋学过程讯息愈来愈 多, 就目前而言, 人们对海水钡的生物地球化学行为 的控制机制仍不清楚, Ba在海洋学和地球化学过程揭 示中的功能开发的非常有限, 亟待开发和研究.

黑潮发源于吕宋海峡以东的菲律宾海域, 从中国 台湾岛东部北上进入东海, 沿东海大陆架外缘向东 北向流动, 在吐噶喇海峡折向东返回太平洋. 其具有 流量大、流速强和高温高盐等特点, 对中国近海尤其 是东海的水文状况、生物区系分布和海底沉积类型 等产生直接影响 (Guo等, 2012; Song, 2010). “中日黑 潮合作调查(the China-Japan Joint Research Program on the Kuroshio(JRK, 1986-1992))”、“黑潮边缘交换过程 (The Kuroshio edge exchange processes(KEEP))”等研究 项目对黑潮及其对邻近海域的影响(Wong等, 2000; 林 葵等, 1995)获得了很多较深刻的认识. 如研究表明吕 宋海峡、台湾东北部海域及日本九州西南海域是黑 潮影响中国近海的3个关键区域(Hsueh, 2000), 黑潮对 东海陆架的入侵程度随季节变化而不同, 夏季时黑潮 主轴远离陆架, 而冬季黑潮水入侵东海范围明显加大 (Chen, 2009). 但总起来看, 除部分研究通过对营养盐 (Guo等, 2012; Zhang J等, 2007)、无机碳(卢汐等, 2016) 等参数的变化特征来探讨黑潮入侵东海的特征外, 大
部分研究集中在海洋动力过程领域, 主要是通过数值 模拟方式来研究黑潮对东海的入侵(刘晓辉等, 2015). 国内外对黑潮主体及邻近东海海域海水中微量元素 的研究报道很少, 对海水中溶解Ba的分布特征、影响 因素等方面则尚未见到相关报道.

本文对海水溶解钡 $(\mathrm{Ba})$ 在台湾以东黑潮主体及邻 近东海海域的地球化学特征及影响因素进行研究, 首 次以 $\mathrm{Ba}$ 为指示指标探究黑潮对东海陆架海水的输入 与影响, 定量估算了黑潮入侵东海的范围与程度, 为 揭示黑潮对东中国海生态环境影响提供依据.

\section{2 材料与方法}

\section{1 调查站位}

通过“科学一号2014年东海春季调查航次”于 2014 年5月 18 日至 6 月 13 日对台湾以东黑潮及东海陆架区 共 40 个站位进行了调查, 站位分布见图1. 调查项目包 括海水的温度、盐度、密度、溶解钡 $(\mathrm{Ba})$ 、硅酸盐、 $\mathrm{pH}$ 和叶绿素 $a$ 等.

\section{2 样品采集、分析及数据处理}

各层水样由CTD控制的Niskin采水器采集. 样品 瓶、滤器等采样及预处理容器预先均用稀硝酸浸泡一 周左右, 使用前先用去离子水、二次蒸馏水和Milli-Q 水冲洗干净. 样品采集后立即用预先处理过的孔径为 $0.45 \mu \mathrm{m}$ 的醋酸纤维膜过滤, 低温保存. 相关操作均按 照海洋监测规范(GB17378-2007, National standard)的 要求进行.

水体温度、盐度和密度 $(\sigma t)$ 等由SBE 911-Plus CTD 进行现场测量. 海水溶解钡 (Ba) 采用直接稀释ICP-MS 法测定, 具体为准确取海水样品 $0.5 \mathrm{~mL}$, 用 $0.5 \%$ 硝酸溶 液稀释定容至 $5 \mathrm{~mL}$, 摇匀, 采用标准加入法建立工作 曲线, 然后上机测定元素的浓度. 在线加入Re做内标, 校正仪器信号漂移. 海水中硅酸盐以硅钿黄分光光 度法测定. pH以 Thermo Orion 5-star pH计(配置雷磁 E-201-D电极) 在 $25^{\circ} \mathrm{C}$ 下对未过滤水样进行测定, 使用 总氢离子浓度标度. 叶绿素 $a(\mathrm{Chl} a)$ 现场以 $0.45 \mu \mathrm{m}$ 孔 径醋酸纤维滤膜过滤, 以F-4600 型苂光分光光度计采 用常规荧光法测定.

利用SPSS15.0软件, 采用Pearson相关性分析来检 


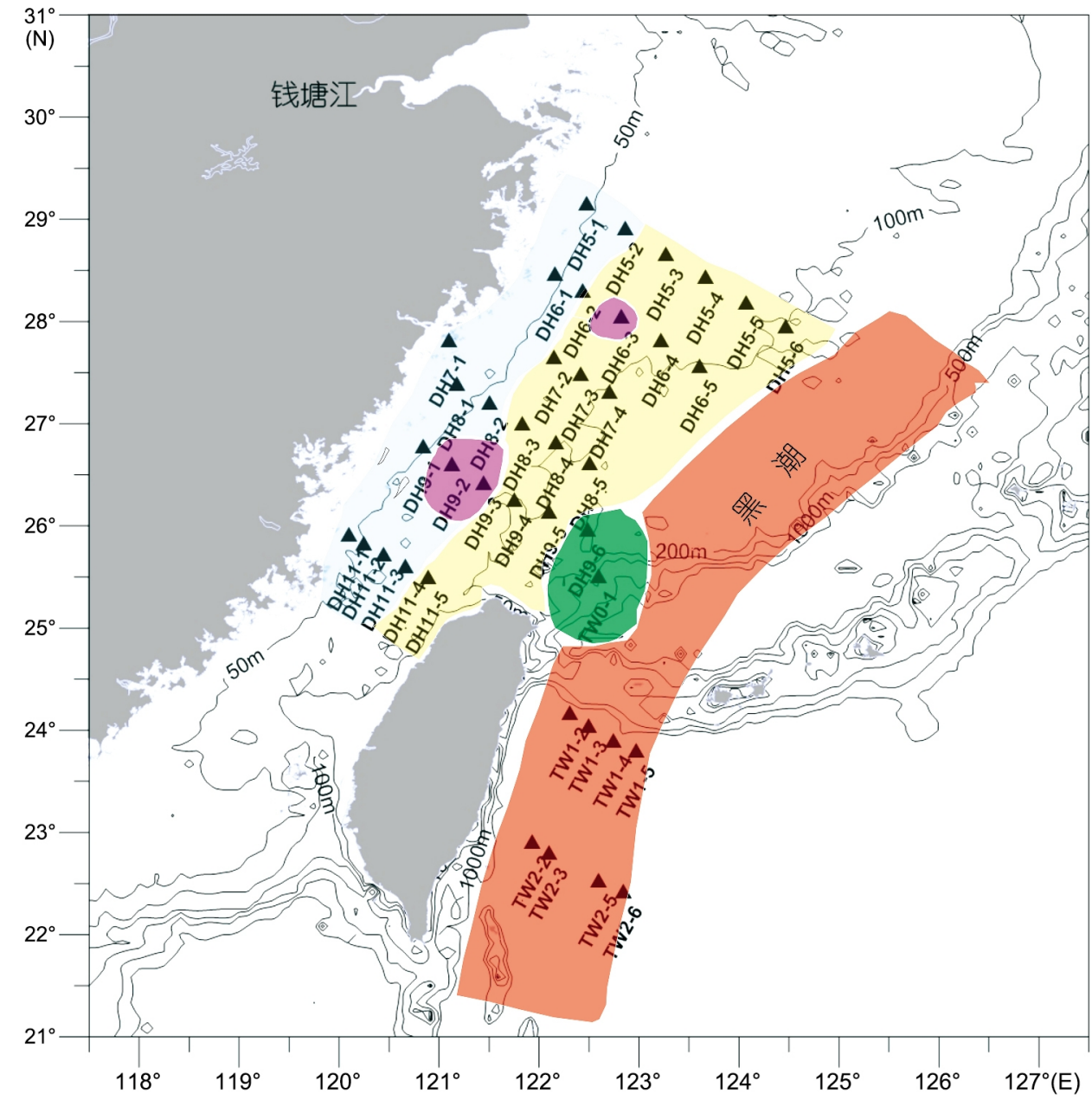

图 1 调查站位及水团分布示意图

蓝色区域代表中国近岸水(CCW), 黄色区域代表台湾暖流水(TCWW), 紫色区域代表陆架垂直混合区(SVMW), 绿色区域代表黑潮上升流 (KUW), 红色区域代表黑潮主流径(Kuroshio mainstream)

验溶解钡 $(\mathrm{Ba})$ 与有关物理-化学参数 (温度、盐度、 硅酸盐、 $\mathrm{pH}$ 和叶绿素 $a$ ) 的相关关系. 采用Origin8.0和 Surfer11.0绘制有关图件.

\section{3 结果与讨论}

\section{1 研究海域的水文环境特征}

\subsection{1 黑潮主流径的水文环境特征}

黑潮主流径呈现出高盐(>34)的特征, 温盐关系呈 现出反S形的分布, 见图2. 同一断面各站水文特征基本 相似. 从垂向分布上来看, 黑潮主流径水体在30 50、 300 500及800 1000m深度出现温盐梯度的显著变化,

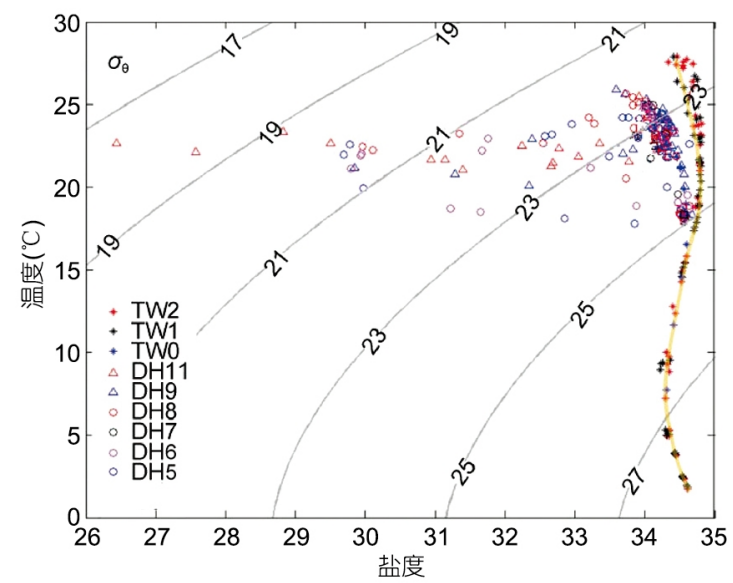

图 2 各调查断面温盐-位密图 
据此在垂向上将黑潮水体分为4层: 表层水(Kuroshio Surface Water, KSW; 水深0 30m)、黑潮次表层水 (Kuroshio Sub-surface Water, KSSW; 水深50 300m)、 黑潮中层水 (Kuroshio Intermediate Water, KIW; 水 深 500 800m)、黑潮深层水 (Kuroshio Deep Water, $\mathrm{KDW} ; 1000 \mathrm{~m}$ 以深). 黑潮主流径的两个断面(TW1、 TW2 断面) 的水文特征相似. 黑潮主体表层温度 平均值 $26.81^{\circ} \mathrm{C}\left(24.24 \sim 27.89^{\circ} \mathrm{C}\right)$, 次表层温度平均值 $20.66^{\circ} \mathrm{C}\left(14.35 \sim 26.39^{\circ} \mathrm{C}\right)$, 中层水及深层水温度平均值 分别为 $7.87^{\circ} \mathrm{C}\left(4.99 \sim 12.83^{\circ} \mathrm{C}\right) 、 2.86^{\circ} \mathrm{C}\left(1.89 \sim 4.02^{\circ} \mathrm{C}\right)$, 各 水层温度向下逐渐降低, 到达 $1000 \mathrm{~m}$ 左右后水温基本 恒定. 盐度以次表层水为最高(34.53 34.82, 平均值 34.73), 以中层水为最低(34.23 34.44, 平均值 34.33), 盐度呈现出表层低(34.34 34.81, 平均值34.59)、次表 层最高、中层水最低、深层水(34.42 34.62, 平均值 34.53)再度升高的特点.

处于黑潮上升流区域中心的TW0-1站位, 同时受 到涌升的黑潮次表层水、中层水及东海陆架水的影 响, 其温盐特点与黑潮主流径不尽相同, 表现出温度、 盐度低于同一深度黑潮主流径海水, 而密度大于同一 深度黑潮主流径海水的特点. TW0-1站位水体与黑潮 主流径水体出现温盐梯度显著变化的水深位置相似, 但水深仅为 $600 \mathrm{~m}$, 据此该站位水体分为 3 层: 表层水 $(0 \sim 30 \mathrm{~m})$ 、次表层水 $(50 \sim 300 \mathrm{~m})$ 、底层水 $(500 \mathrm{~m}$ 以深 $)$.

\subsection{2 东海陆架区的水文环境特征}

受陆源淡水、台湾暖流及东侧黑潮的共同影响, 东海陆架区的温度、盐度呈现出较大的变化范围. 根 据本次调查水文结果和以往参考资料, 东海陆架区包 括中国近岸水(China Costal Water, CCW)、台湾暖流 水(Taiwan Current Warm Water, TCWW)、陆架垂直混 合水(Shelf Vertical Mixed Water, SVMW)3 个主要区域. 靠近大陆的为中国近岸水 $(\mathrm{CCW})$, 由于大量低温、低 盐的陆源淡水输入, $\mathrm{CCW}$ 海水表层温度和盐度均低 于外海海区. 随着水深的增加, 温度略有降低、盐度 升高. 某些近岸站位在10 30m层处出现温度和盐度 跃层, 出现外海高温高盐水近岸顶升的现象. 东海陆 架外缘站位则受台湾暖流(TCWW) 的控制, 表层盐度 大于 33 , 并且温度较高. 相关研究表明, TCWW区上 层海水来自于温度较高的台湾海峡水流, 而下层海水 则为较冷的黑潮水(Guan和Fang, 2006), 因此调查结果
显示陆架外侧站位垂向盐度变化较小, 在50 80m出现 明显的温跃层. DH9-3、DH9-2、DH6-3站位位于 $60 \mathrm{~m}$ 等深线附近, 上述站位温度、盐度垂向变化很小, 体 现出海水垂直混合的特点, 本文记为陆架垂直混合水 (SVMW). 与TW0-1站位相近的DH9-6站位受到黑潮涌 升的影响, 盐度较高, 水温较低且无明显跃层.

\section{2 海水中溶解Ba的地球化学特征}

\subsection{1 黑潮主流径海水中溶解Ba的分布及影响因素}

黑潮主流径各站位溶解Ba浓度分布范围在 4.91 19.2 $\mu \mathrm{g} \mathrm{L}^{-1}$, 平均值约为 $10.51 \mu \mathrm{g} \mathrm{L}^{-1}$. 垂直分布 上, 表层水浓度最低, 分布范围为4.91 5.96 $\mu \mathrm{g} \mathrm{L}^{-1}$, 平 均值为 $5.52 \mu \mathrm{g} \mathrm{L}^{-1}$; 次表层水 $\mathrm{Ba}$ 的浓度开始升高, 分 布范围为5.36 11.51 $\mu \mathrm{g} \mathrm{L}^{-1}$, 平均值为 $7.45 \mu \mathrm{g} \mathrm{L}^{-1}$; 中层 水 $\mathrm{Ba}$ 浓度继续升高, 分布范围为 $10.05 \sim 17.19 \mu \mathrm{g} \mathrm{L}^{-1}$, 平均值为 $14.13 \mu \mathrm{g} \mathrm{L}^{-1}$; 深层水浓度最高, 分布范围为 $16.81 \sim 19.20 \mu \mathrm{g} \mathrm{L}^{-1}$, 平均值为 $18.17 \mu \mathrm{g} \mathrm{L}^{-1}$. 黑潮主流径 各站位Ba的浓度分布相同, 均呈现出从表层至深层浓 度逐渐增高的特点, 各站位 $\mathrm{Ba}$ 的垂直分布特征如图3 所示. TW1 断面和 TW2 断面海水 Ba的含量相差不大, TW2 断面略小. $100 \mathrm{~m}$ 以浅深度Ba的浓度增加较慢, 海 水深度低于 $100 \mathrm{~m}$ 后, Ba浓度快速增加. 黑潮主流径海 水中 $\mathrm{Ba}$ 的浓度与世界其他海区海水中 $\mathrm{Ba}$ 浓度的比较 见表1.

海水中 $\mathrm{Ba}$ 的分布主要受海水混合及生物利用、 钡盐化学平衡因素的影响. 本次调查的结果显示, 黑 潮主体海水中 $\mathrm{Ba}$ 与硅酸盐表层海水最低, 越向深处数 值越高, 它们之间呈现出明显的正相关性, 而 $\mathrm{Ba}$ 与 $\mathrm{pH}$ 呈负相关, 见图4. 黑潮主体叶绿素 $a$ 的含量则是表层 较高, 向下逐渐降低, 至 $200 \mathrm{~m}$ 深处时, 黑潮主流径各站 位叶绿素 $a$ 含量已低于检出限. 这说明黑潮表层水中 浮游植物活动活跃, 因有硅藻等浮游植物的生长繁殖, 海水中的 $\mathrm{Ba}$ 和 $\mathrm{Si}$ 被消耗, 导致其在海水中的含量较低. 随着深度的增加, 海水温度降低, 浮游植物等生物活 动减弱, 但是生物死亡形成的生源颗粒物逐渐沉降, 由于海水对其降解作用, 造成中层水和深层水中 $\mathrm{Ba}$ 的 浓度增大, 使得 $\mathrm{Ba}$ 得以再生进入深层水中, 这种特点 与海水中 $\mathrm{Si}$ 的特点相似, 并在世界多数海区得以证实 (Jeandel等, 1996; Horner等, 2015; Cao等, 2016). 根据文 献与本次调查, 黑潮水体中溶解氧(Dissolved oxygen) 

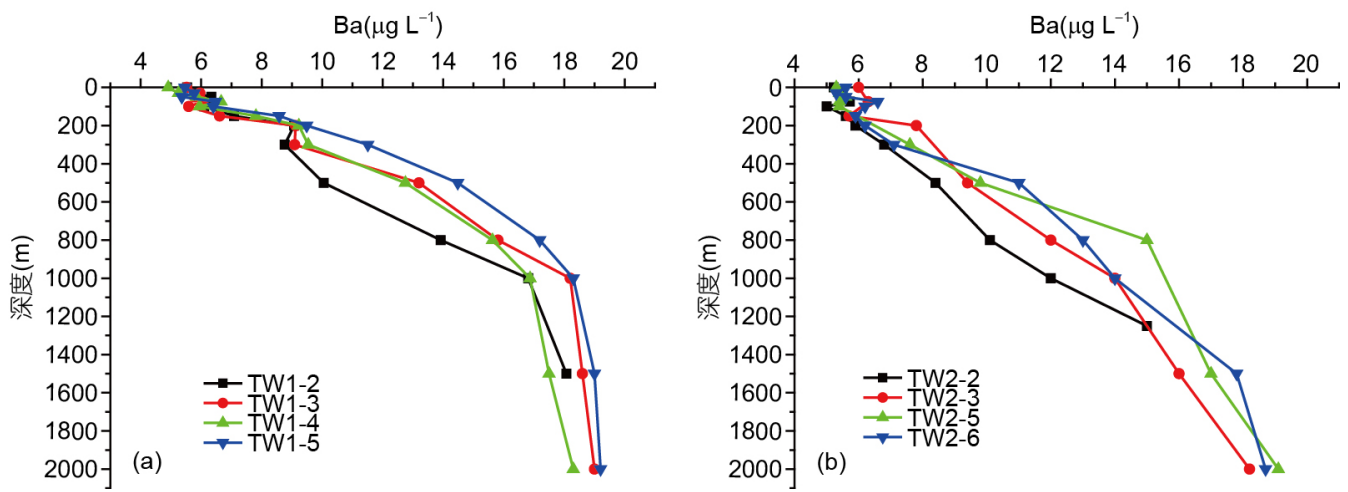

图 3 黑潮主流径海水溶解 $\mathrm{Ba}$ 的垂直分布

表 1 世界其他海区海水中溶解 Ba的浓度

\begin{tabular}{ccccc}
\hline 海区 & 时间 & 水深 $(\mathrm{m})$ & $\mathrm{Ba}\left(\mu \mathrm{g} \mathrm{L} \mathrm{L}^{-1}\right)$ & 参考文献 \\
\hline 南印度洋 & $1985-02 \sim 1985-03,1986-03 \sim 1986-05$ & & & Jeandel等 $(1996)$ \\
南大西洋 & $1987-01 \sim 1987-02$ & 5000 & $4.21 \sim 16.84$ & Horner等 $(2015)$ \\
南中国海 & - & 4500 & $6.12 \sim 14.02$ & Cao 等 $(2016)$ \\
北冰洋 & $2010-01$ & 3600 & $5.39 \sim 19.17$ & Roeske等 $(2012)$ \\
南极洲威德尔海 & 2007 & 250 & $4.25 \sim 13.55$ & Hoppema等 $(2010)$ \\
孟加拉湾 & $2006-01 \sim 2006-04$ & 5000 & $0.51 \sim 15.01$ & Singh等 $(2013)$ \\
\hline
\end{tabular}
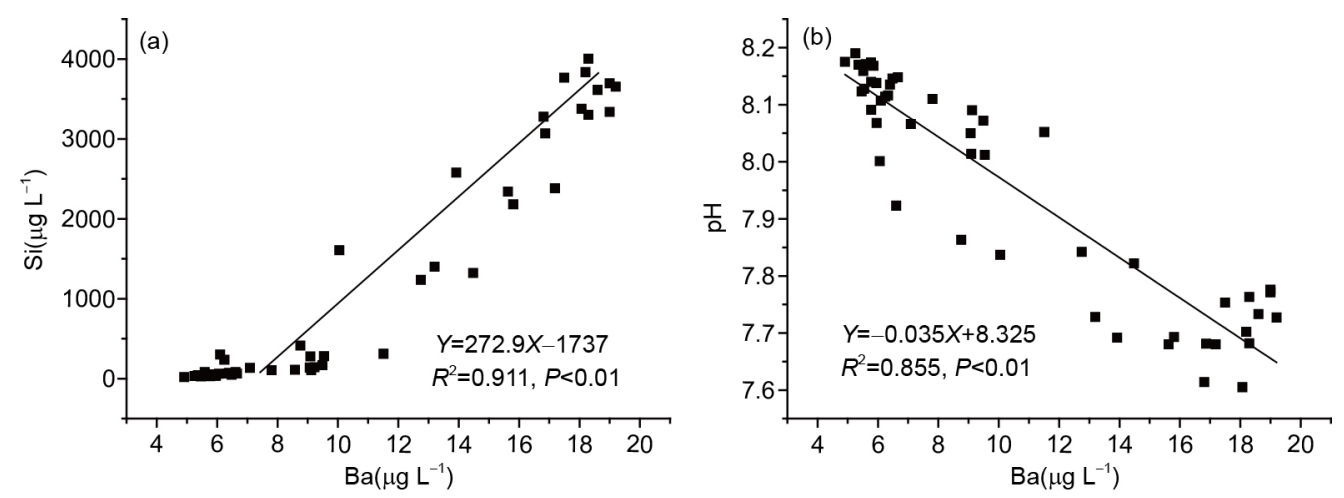

图 4 黑潮主流径海水 $\mathrm{Ba}$ 与 $\mathrm{Si} 、 \mathrm{pH}\left(25^{\circ} \mathrm{C}\right)$ 的相关性

含量最小值出现在800 1000m水层(Sheu等, 1996), 也 从侧面证实中层水中存在着生源颗粒物的耗氧降解 进而向海水中释放 $\mathrm{Ba}$ 的过程.

$\mathrm{Ba}$ 在海水颗粒物的存在形式主要是 $\mathrm{BaSO}_{4}$ 等盐类 (Monnin和Cividini, 2006), 在 $\mathrm{Ba}^{2+}$ 从颗粒态向海水中释 放的过程中, $\mathrm{pH}$ 发挥着重要的作用. 随着深度的增加, 在向低温低盐的中层水过渡过程中, 有机物不断降解 生成游离 $\mathrm{CO}_{2}$, 进而导致 $\mathrm{pH}$ 逐渐降低, 至深层水达到最
低, 海水酸性增强, 海水总碱度升高. 海水酸性的增大 更有利于颗粒态 $\mathrm{BaSO}_{4}$ 等溶解, 这一过程进一步导致 了海水中 $\mathrm{Ba}$ 浓度的升高.

在深层水中, 水温降低、压力增大, 导致 $\mathrm{BaSO}_{4}$ 等 盐类的表观溶度积常数 $\mathrm{K}_{\mathrm{sp}}$ 升高, $\mathrm{Ba}^{2+}$ 离子与 $\mathrm{BaSO}_{4}$ 的 化学平衡向形成离子方向移动(Monnin, 1999), 这是深 层水中 $\mathrm{Ba}$ 浓度升高的重要原因. 在深层水中 $\mathrm{BaSO}_{4}$ 一 般呈不饱和状态(Monnin和Cividini, 2006), 故Ba浓度 
有进一步增大的空间, 这与海水中 $\mathrm{CaCO}_{3}$ 的特点相似. Sheu等(1996)与Chen等(2006)的调查研究指出, 在台湾 东北黑潮 $1000 \mathrm{~m}$ 以深水体中, 溶解氧浓度随水深增加 而上升, 由此可知在黑潮深层水中, 生源颗粒物分解 已基本完成, 此时 $\mathrm{BaSO}_{4}$ 的化学平衡溶解会影响海水 $\mathrm{Ba}$ 分布.

因此, 黑潮主体溶解Ba垂直向下逐渐增高的浓度 分布主要由 3 个因素造成, 一是海水中含 $\mathrm{Ba}$ 生源颗粒 物的降解; 二是随深度增加, 海水 $\mathrm{pH}$ 降低, 酸性增强, 进一步促进颗粒态 $\mathrm{BaSO}_{4}$ 盐类的溶解; 三是在深层水 中, 水温降低、压力增大, 导致 $\mathrm{BaSO}_{4}$ 等盐类的表观溶 度积常数 $\mathrm{K}_{\mathrm{sp}}$ 升高, 致使化学平衡向形成 $\mathrm{Ba}^{2+}$ 方向移动.

\subsection{2 台湾东北部上升流区海水中 $\mathrm{Ba}$ 的分布及影响因 素}

TW0-1站位位于黑潮上升流区, 同时受到东海陆 架区海水和黑潮水的影响, Ba的浓度与黑潮主流径不 尽相同. 表层、次表层及底层水的Ba的浓度平均值分 别为6.66、8.64及 $14.73 \mu \mathrm{g} \mathrm{L}^{-1}$, 亦呈现出向海水深处 $\mathrm{Ba}$ 浓度增加的趋势, 说明影响该站位Ba分布的因素与黑 潮主流径一致. TW0-1站位Ba浓度和邻近的黑潮主流 径TW1断面各站位同一水层Ba浓度平均值垂直分布 对比见图5, 可以看出各层 $\mathrm{Ba}$ 的浓度分别高于黑潮主 流径站位相应各层的浓度, 体现出下方水层的影响. 如该站位底层 $(500 \mathrm{~m}$ 水深 $) \mathrm{Ba}$ 的浓度为 $14.73 \mu \mathrm{g} \mathrm{L}^{-1}$, 与 黑潮主流径中层水Ba浓度的平均值相近, 体现出了黑 潮中层水涌升的影响. 由于上升流的存在, 导致TW0-1 站位 $\mathrm{pH}$ 偏低, 总碱度升高, 这与 $\mathrm{Ba}$ 的分布存在一致性, 显示出了下方水层的影响.

\subsection{3 东海陆架区海水Ba的分布特征及影响因素}

东海陆架区海水中 $\mathrm{Ba}$ 的分布受陆源河流输入、 外海黑潮入侵、生物活动等多种因素的影响, 空间分 布有着显著的差异. 总体来看, 近岸水域海水中 $\mathrm{Ba}$ 的 浓度要高于远海处, 这与陆源高Ba浓度河水输入有关.

调查海域表层海水 $\mathrm{Ba}$ 浓度分布范围为 $4.91 \sim 18.61 \mu \mathrm{g} \mathrm{L}^{-1}$, 平均值约为 $9.09 \mu \mathrm{g} \mathrm{L}^{-1}$. 由表层 $\mathrm{Ba}$ 的 平面分布可见, 受来陆源含高浓度 $\mathrm{Ba}$ 河水的输入 $(\mathrm{Wu}$ 等, 2009), 靠近大陆的近岸水区 $(\mathrm{CCW}) \mathrm{Ba}$ 的浓度最高. 调查海域表层Ba浓度与叶绿素 $a$ 的相关性明显(图6), 这说明陆源排入的高 $\mathrm{Ba}$ 含量河水有利于海水中硅藻 等浮游植物的生长. 陆架垂直混合区处的Ba浓度在表

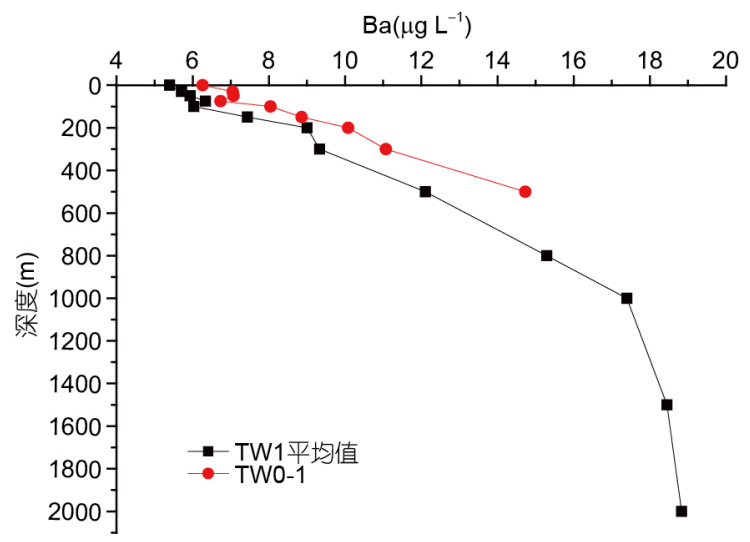

图 5 TW0-1站位与黑潮主流径海水溶解Ba浓度对比

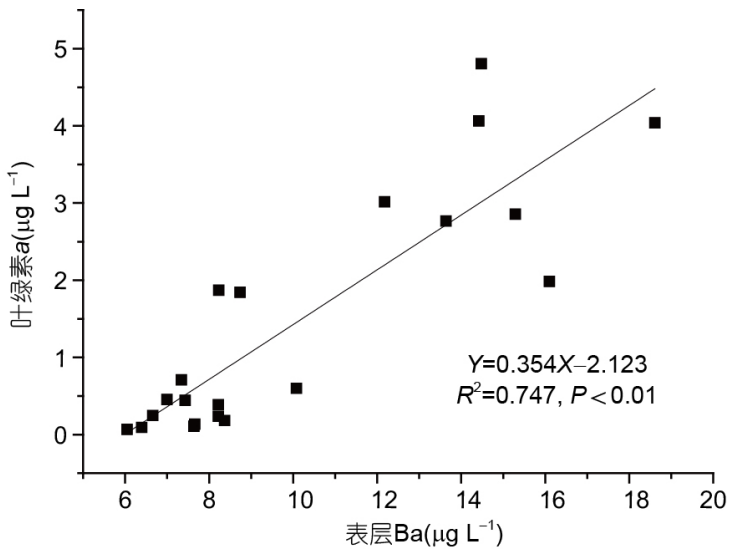

图 6 东海表层海水溶解 $\mathrm{Ba}$ 与叶绿素 $a$ 的相关性

层水中表现的特征并不十分明显, 其浓度介于近岸水 区 $(\mathrm{CCW})$ 和台湾暖流区 $(\mathrm{TCWW})$ 之间. 台湾暖流区表 层水由于受到台湾海峡水的影响, 其 $\mathrm{Ba}$ 含量居于中间 位置. 相比之下, 台湾以东黑潮主体的Ba浓度均小于 东海陆架区的站位, 这于黑潮表层叶绿素 $a$ 低的特点一 致, 说明黑潮主体表层的初级生产力水平较低. DH9-6 和TW0-1站位位于黑潮上升流区, 受黑潮次表层水涌 升的影响, 其 $\mathrm{Ba}$ 的浓度要高于黑潮表层水.

$30 \mathrm{~m}$ 层位于本次调查黑潮表层水下边界附近, 而 且东海陆架区调查站位均能到达 $30 \mathrm{~m}$ 水深. $30 \mathrm{~m}$ 层海 水整体上 $\mathrm{Ba}$ 的分布范围为5.25 17.43 $\mu \mathrm{g} \mathrm{L}^{-1}$, 平均值约 为 $8.34 \mu \mathrm{g} \mathrm{L}^{-1}$, 平面分布见图 $7 \mathrm{~b}$. 与黑潮主流径 $\mathrm{Ba}$ 的分 布特点随深度增加不同的是, 大部分站位东海 $30 \mathrm{~m}$ 层 $\mathrm{Ba}$ 相较于表层来说反而要小, 这说明浮游植物的活动 固定了海水中的大量 $\mathrm{Ba}$, 至 $30 \mathrm{~m}$ 深度时生源颗粒物尚 未溶解，海水中Ba尚未得到补充，从而造成了 $30 \mathrm{~m}$ 层 

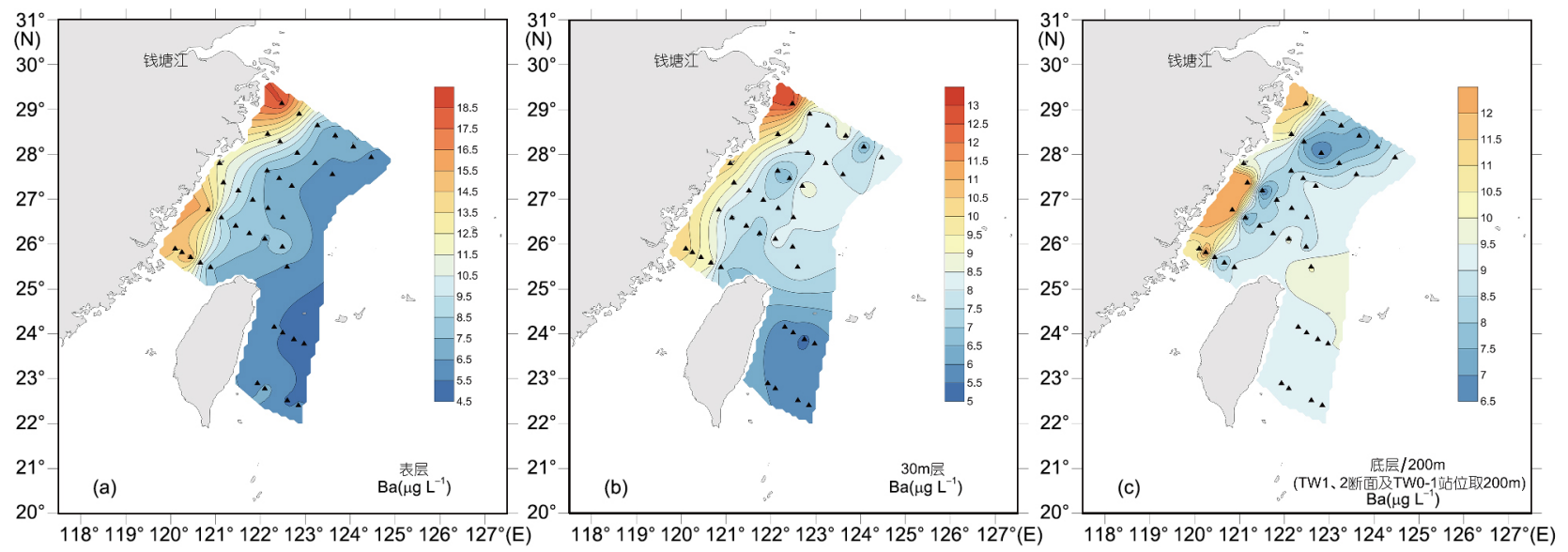

图 7 调查海域海水溶解 $\mathrm{Ba}$ 的平面分布

Ba浓度的降低. 而DH11断面则呈现出30m层浓度高 的特点, 原因为DH11断面位于台湾海峡水的北向出 口处, 台湾海峡水是由南海水和经吕宋海峡侵入的黑 潮水共同组成, 其与黑潮主流的性质接近, 向深处 $\mathrm{Ba}$ 浓度要高于表层. 中国近岸水区北部温、盐跃层多在 20 30m, 30m水层处于跃层之下, 但受长江、钱塘江 陆源输入影响仍然显著, 近岸水区南部同样受到沿岸 河流输入的影响, $30 \mathrm{~m}$ 层均出现Ba浓度的高值. 从 $30 \mathrm{~m}$ 层 $\mathrm{Ba}$ 的平面分布图来看, 台湾海峡水含有较低的 $\mathrm{Ba}$ 含 量, 从台湾岛西侧向北, 在东海陆架上向正北方向延 伸, 能够到达东海陆架的中部 $29^{\circ} \mathrm{N}$ 位置. 处于上升流 区的DH9-6和TW0-1站位Ba浓度要高于黑潮主流径, 体现出黑潮较深层水的涌升.

东海陆架底层地形与海流对底层 $\mathrm{Ba}$ 的分布起着 重要的影响. 黑潮主流径站位水深均大于 $500 \mathrm{~m}$, 本文 采用代表黑潮次表层水、相当于外陆架大陆坡折深 度 $200 \mathrm{~m}$ 深处的黑潮水与东海陆架底层水进行比较分 析. 东海陆架底层(黑潮主流径各站和TW0-1站取水 深 $200 \mathrm{~m}$ ) 海水 $\mathrm{Ba}$ 的分布范围为 $7.06 ~ 13.83 \mu \mathrm{g} \mathrm{L}^{-1}$, 平均 值约为 $9.25 \mu \mathrm{g} \mathrm{L}^{-1}$, 平面分布见图7c. 从垂向分布上来 看, 陆源高 $\mathrm{Ba}$ 含量河水输入海洋后从表层向下扩散, 导致 CCW区垂向变化相对较大, 底层浓度要小于表层 和 $30 \mathrm{~m}$ 层; 而台湾暖流区 $(\mathrm{TCWW})$ 底层 $\mathrm{Ba}$ 的浓度垂向 上是最高的, 这是由于 TCWW区海水深度增加(水深 70 90m), 由于生源颗粒物的溶解、海底沉积物向海 水释放 $\mathrm{Ba}$ 等原因, $\mathrm{Ba}$ 的浓度升高. 在垂向混合剧烈的 陆架垂直混合区 (SVMW海区), 底层Ba的浓度与上方 水层浓度变化不大, 出现Ba浓度的低值. 总起来看, 底
层平面分布上以 CCW区的近岸海水Ba浓度为最高, 受 黑潮影响的陆架外侧站位次之, 而二者之间中部出现 南北方向的低值区. 陆架外侧黑潮的影响开始向西北 方向扩大, 逐步向陆架方向入侵, 陆架外侧 $\mathrm{Ba}$ 的浓度 要高于台湾海峡水.

\subsection{4 东海陆架DH9断面Ba的分布及影响因素}

本次调查的DH9断面位于台湾北部, 调查站位横 跨陆架并与 TW0-1站位相接. 本文将 TW0-1站位作为 DH9断面一部分进行分析. DH9断面Ba的分布情况见 图8. 由图可以看出,近岸的DH9-1站位从表层至底层 均受河流输入的影响, 出现 $\mathrm{Ba}$ 浓度的高值. 受黑潮影 响明显的外侧TW0-1和DH9-6站位Ba浓度次之, 且自 上而下逐渐升高, 体现出了黑潮沿底层向上爬升的次 表层水的影响. 位于断面中间的DH9-4、DH9-3等站 位出现 $\mathrm{Ba}$ 浓度的最低值, 其浓度与代表台湾海峡水的 DH11断面东侧站位Ba浓度相近, 说明此处受到从台 湾岛西侧北上的台湾海峡水的主导.

\section{3 黑潮与东海陆架区水体 $\mathrm{Ba}$ 的交换通量}

获取黑潮向东海的物质输入通量需要首先明确 东海陆架的水盐收支情况, 以在此基础上计算黑潮与 东海的水交换通量. 东海陆架区与外部的主要水交换 途径包括河流(长江)、降雨/蒸发、台湾海峡、对马 海峡、黄东海交换、黑潮、东海陆架边缘交换. 本文 根据箱式模型水盐平衡关系式(1)计算黑潮与东海陆 架区的水交换通量(Atkinson, 2010). 根据本次调查结 果, 黑潮向东海陆架的水输送通量同时考虑黑潮表层 


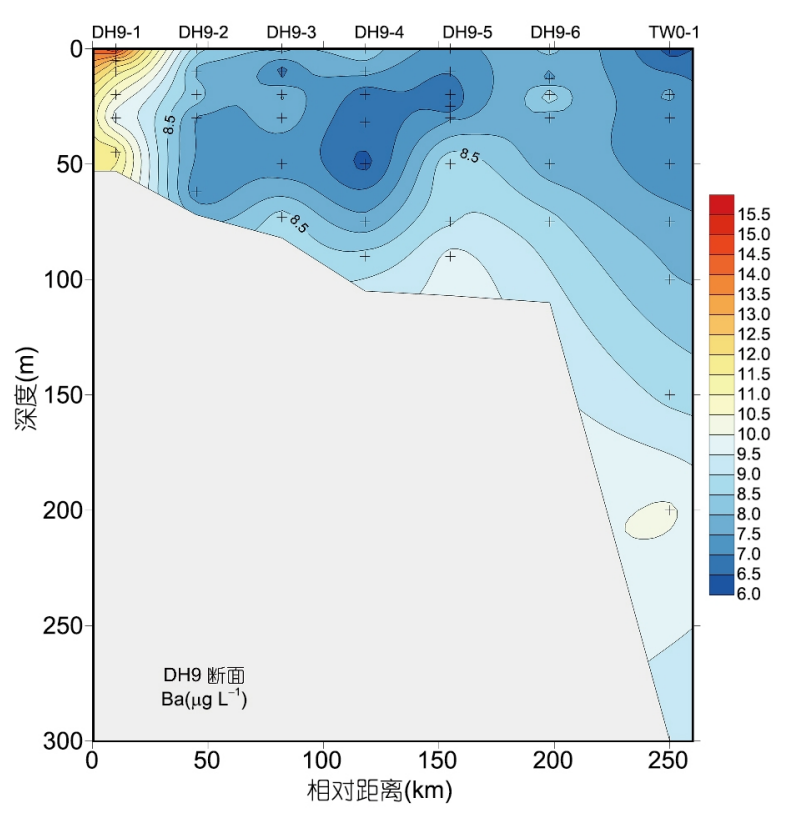

图 8 DH9断面海水溶解Ba分布

水、次表层水及中层水. Chen等(1995)给出了黑潮表 层水、次表层水及中层水的温盐范围, 并将5 10月间 (雨季)进入东海陆架的KSW(黑潮表层水):KSSW(黑潮 次表层水): $\mathrm{KIW}$ (黑潮中层水)平均水通量比例确定为 3:3:1(Chen, 1996, 1998; Chen和Wang, 1999). 其各层水 温盐范围及划分与本文研究结果相似(3.1.1节), 因此 本文参照上述文献的研究结果, 按照KSW:KSSW:KIW
平均水通量比例为 $3: 3: 1$ 计算黑潮与东海陆架的水交 换通量, 进而得出黑潮与东海陆架 $\mathrm{Ba}$ 的交换通量.

$$
\sum Q_{i}=0, \sum\left(Q_{i} \times \rho_{i} \times S_{i}\right)=0,
$$

式中, $Q_{i}$ 代表海水体积通量, $\rho_{i}$ 代表水体密度, $S_{i}$ 代表水 体盐度.

黑潮各层水体在5 10月(雨季)向东海陆架区输送 及从陆架区向外输送 $\mathrm{Ba}$ 的情况见表 2 . 可见黑潮次表 层水向东海陆架输送 $\mathrm{Ba}$ 的通量为最大, 表层水次之, 而中层水最小. 黑潮水向东海陆架输送Ba通量共计为 $2.19 \times 10^{8} \mathrm{~kg} /$ 半年, 东海水通过陆架边缘向黑潮输送的 $\mathrm{Ba}$ 的通量为 $0.82 \times 10^{8} \mathrm{~kg} /$ 半年, 因此黑潮向东海陆架区 $\mathrm{Ba}$ 的净输入通量为 $1.37 \times 10^{8} \mathrm{~kg} /$ 半年. 东海水通过对马 海峡向外海输出的 $\mathrm{Ba}$ 量为 $3.56 \times 10^{8} \mathrm{~kg} /$ 半年, 占东海向 外输出 $\mathrm{Ba}$ 的大部分, 并且超过了黑潮水的总输入量.

\section{4 海水溶解钡(Ba)对黑潮入侵东海范围与程度的 指示作用}

\subsection{1 溶解钡 $(\mathrm{Ba})$ 对黑潮入侵东海的指示}

从东海陆架区表层和 $30 \mathrm{~m}$ 层 $\mathrm{Ba}$ 的分布结果(图7) 看出, 陆架外侧的站位表层至 $30 \mathrm{~m}$ 层主要受控于台湾 海峡水, 来自台湾海峡的低Ba浓度水流从海峡北端出 口东侧向北, 可到达东海陆架的中南部, 而来自东部更 低Ba浓度的黑潮表层水则受到了台湾海峡北向出水

表 2 东海陆架区水交换通量与 $\mathrm{Ba}$ 的收支(5 10月, 雨季 $)^{\mathrm{a})}$

\begin{tabular}{|c|c|c|c|c|c|c|c|c|}
\hline & 交换项 & 盐度 & $\begin{array}{c}\text { 密度 } \\
\left(\mathrm{kg} \mathrm{m}^{-3}\right)\end{array}$ & $\begin{array}{c}\text { 水通量 } \\
(\mathrm{Sv})\end{array}$ & $\begin{array}{l}\mathrm{Ba} \text { 浓度 } \\
\left(\mu \mathrm{g} \mathrm{L}^{-1}\right)\end{array}$ & $\begin{array}{c}\mathrm{Ba} \text { 输送通量 } \\
\left(\mathrm{kg} \mathrm{s}^{-1}\right)\end{array}$ & $\begin{array}{c}\mathrm{Ba} \text { 半年输送 } \\
\text { 量 }\left(\times 10^{8} \mathrm{~kg} /\right. \\
\text { 半年 })\end{array}$ & 参考文献 \\
\hline & 河流(长江) & 0.18 & 1000 & 0.040 & - & - & - & $\begin{array}{c}\text { 中华人民共和国水 } \\
\text { 利部(2013) }\end{array}$ \\
\hline 输 & 降雨/蒸发 & 0.00 & 1000 & 0.0264 & - & - & - & Chen 和 Wang (1999) \\
\hline 入 & 台湾海峡水 & 34.0 & 1022 & 1.63 & - & - & - & 郭景松等(2005) \\
\hline \multirow[t]{3}{*}{ 项 } & 黑潮表层水 & 34.59 & 1022 & 0.781 & 5.52 & 4.31 & 0.69 & - \\
\hline & 黑潮次表层水 & 34.73 & 1024 & 0.781 & 7.45 & 5.82 & 0.92 & - \\
\hline & 黑潮中层水 & 34.33 & 1027 & 0.260 & 14.13 & 3.67 & 0.58 & - \\
\hline 输 & 东海陆架边缘 & 33.42 & 1023 & 0.660 & 7.926 & 5.23 & 0.82 & - \\
\hline 出 & 对马海峡 & 33.6 & 1027 & 2.85 & 7.926 & 22.59 & 3.56 & Fukudome等(2010) \\
\hline 项 & 黄东海交换 & 32.7 & 1025 & 0.009 & - & - & - & Hong等(2002) \\
\hline
\end{tabular}

a) $\mathrm{Sv}=106 \mathrm{~m}^{3} \mathrm{~s}^{-1}$; 表中输出项为“-”; 5 10月半年以 184 日计算; 台湾海峡、对马海峡水通量为计算所得的5 10月平均值 
的抑制，被限定在陆架的东南部，这与 Guan 和 Fang(2006)、 Li等(2014)、Guo等(2003)研究中关于台 湾海峡北向出水抑制黑潮表层水入侵, 台湾暖流表层 水来自于台湾海峡的结论一致. 在外侧陆架底层, $\mathrm{Ba}$ 的浓度较陆架中部高, 呈现出黑潮次表层水的特点, 黑潮水的影响范围向西北扩大, 从黑潮区开始, 沿黑 潮上升流区的TW0-1站位向西北逐步向大陆方向入 侵, 从后文端元分析来看, 黑潮水最远处能到达钱塘 江口附近, 这造成了陆架底层中部海水Ba浓度偏高. 上升流区中心的 TW0-1站位各层Ba的浓度分别高于 黑潮主流径站位相应水层的浓度, 体现出下方水层的 影响, 说明黑潮在此处通过涌升侵入东海陆架.

\subsection{2 黑潮入侵东海范围与程度的定量评估}

黑潮对东海入侵的范围、程度及变化特征一直 是海洋学多年来的关注焦点. 温盐数据是最容易获得 的数据, 是海洋研究中的经典指标, 传统上一般采用 温-盐图解法来定量确定海水水团的混合情况. 后期海 洋水团混合研究中开始引入端元计算模式, 引入第三 个参数来定量计算水团混合比(Miller, 1950; Tomczak, 1981), 以较为精确的分析水团混合情况, 通常可采用 矩阵运算的方式得出, 式(2)(Zhang L 等, 2007). 本文以 海水中的 $\mathrm{Ba}$ 为指示指标, 结合盐度等参数来研究黑潮 对东海的入侵范围和程度, 研究 $\mathrm{Ba}$ 作为指示指标的有 效性.

$$
\left(\begin{array}{cccc}
1 & 1 & 1 & 1 \\
T_{11} & T_{12} & \cdots & T_{1 n} \\
\vdots & \vdots & \cdots & \vdots \\
T_{m 1} & T_{m 2} & \cdots & T_{m n}
\end{array}\right)\left(\begin{array}{c}
f_{1} \\
f_{2} \\
\vdots \\
f_{n}
\end{array}\right)=\left(\begin{array}{c}
1 \\
T_{1}^{\mathrm{obs}} \\
\vdots \\
T_{m}^{\mathrm{obs}}
\end{array}\right),
$$

式中, $f_{i}(i=1,2, \ldots, n)$ 是第 $i$ 个水团的贡献百分数; $T_{i j}$ 是第 $i$ 个水团第 $j$ 个指标的值; $T_{j}^{\mathrm{obs}}$ 是某一调查站点第 $j$ 个指 标的实测值.

从前面的讨论和图7可以看出, 影响东海陆架区的 水团以黑潮表层水、黑潮次表层水、台湾海峡水、中 国近岸水这几个端元为主. 各端元参数取值以本次调 查期间水文参数作为依据, 黑潮表层与次表层水取主 流径相应采样点(TW1和TW2断面的 8 个站位)数据的 平均值, 台湾海峡水取DH11断面东侧站点(DH11-4、 DH11-5)数据的平均值, 中国近岸水取各断面靠近大陆 最近站点(DH5-1、DH6-1、DH7-1、DH8-1、DH9-1、 DH11-1)数据的平均值, 详见表3.
表 3 各端元指标值

\begin{tabular}{cccc}
\hline 端元(水团) & 盐度 & 温度 $\left({ }^{\circ} \mathrm{C}\right)$ & $\mathrm{Ba}\left(\mu \mathrm{g} \mathrm{L}{ }^{-1}\right)$ \\
\hline 黑潮表层水 & $34.59 \pm 0.14$ & $26.81 \pm 1.11$ & $5.52 \pm 0.33$ \\
黑潮次表层水 & $34.73 \pm 0.09$ & $20.66 \pm 3.40$ & $7.45 \pm 0.38$ \\
台湾海峡水 & $33.96 \pm 0.53$ & $24.95 \pm 0.89$ & $6.61 \pm 0.48$ \\
中国近岸水 & $29.83 \pm 2.34$ & $21.16 \pm 1.11$ & $15.29 \pm 2.13$ \\
\hline
\end{tabular}

黑潮表层水通过向西扩展的方式对东海表层海 水产生影响, 其与台湾海峡水、大陆沿岸水一起影响 着东海表层水的生态环境, 并形成了东海表层水这一 独立水团( $\mathrm{Qi}$ 等, 2014). 采用式(2), 使用 $\mathrm{Ba}$ 和盐度作为 指标计算各水团端元比例, 结果显示黑潮表层水对本 次调查站位产生的影响很小, 即便是距离黑潮主流径 最近的TW0-1站位处, 黑潮表层水所占比例也同样很 低. 采用盐度和温度作为计算指标也得出了同样的结 论. 从该站位表层的 $\mathrm{Ba}$ 浓度、位温及盐度来看, 各项 指标均与黑潮次表层水相近, 说明黑潮次表层水在此 处可涌升至表层, 形成了卫星观测到的台湾东北部冷 窝(Zhang等, 2015). 黑潮表层水对东海的入侵随季节 显著不同, 在冬季可入侵至 $100 \mathrm{~m}$ 等深线处的位置, 春 季的影响范围要小于冬季(Chen, 2009). 本次调查位于 春季, 且各断面最外侧站位基本位于 $100 \mathrm{~m}$ 等深线附 近, 因此黑潮表层水几乎未能影响到本次调查东海陆 架区各站位表层海水.

东海陆架海域底层主要受到黑潮次表层水、台 湾海峡水及中国近岸水这三个端元的影响, 采用式(2) 计算可得出黑潮水在东海陆架海域各站位底层所占 的比例, 见图9. 其中图 $\mathrm{a}$ 是采用 $\mathrm{Ba}$ 和盐度作为指标得 出的结果, 图 $\mathrm{b}$ 是采用盐度和温度作为指标得出的结 果. 由图9a可以看出, 陆架中部出现向西北近岸方向 突起的黑潮水比例高值锋面, 至钱塘江口附近黑潮水 所占比例仍旧能达到 $65 \%$ 左右, 这说明黑潮水冲出台 湾以东后, 在向东北转弯的过程中, 由于缺少台湾岛的 阻挡和海底地形的影响, 有一支黑潮水脱离黑潮主轴, 沿陆架底层向上爬升, 从台湾东北海域沿陆架中部向 西北方向侵入, 最远处能够到达钱塘江口附近. 陆架 东南部受到近岸水和北上的台湾海峡水影响明显, 黑 潮水所占比例在DH8-2、DH9-3站位附近快速降低到 $50 \%$. 陆架底层外侧大部分被黑潮水所控制, 黑潮水 在 $100 \mathrm{~m}$ 等深线处的调查站位以外能够达到 $95 \%$ 以上 

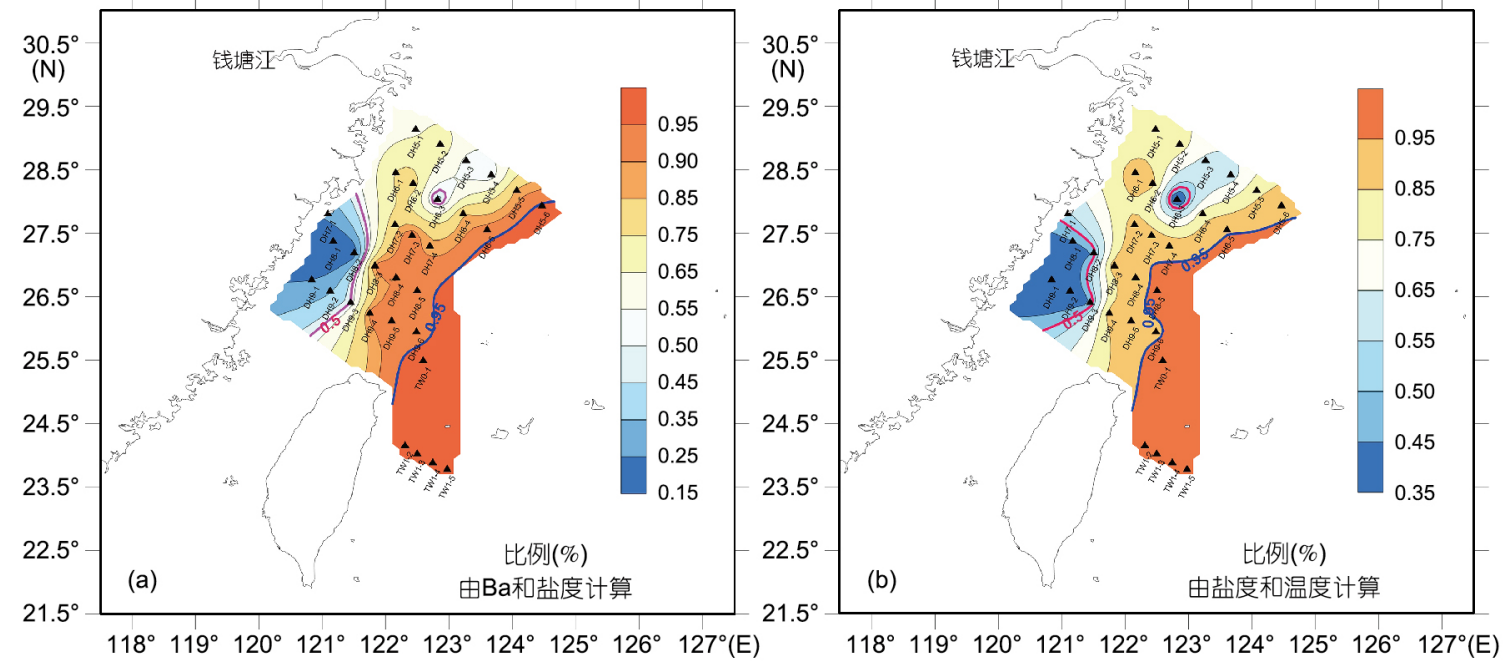

图 9 东海陆架底层黑潮水所占比例

的比例. 入侵至钱塘江口的黑潮水和陆架外侧占主导 地位的黑潮水之间的DH6-3、DH5-4站位处黑潮水分 布较少, 比例较低. Yang等(2011, 2012)基于ROMS模 式(Regional Ocean Model System)分析指出黑潮次表层 水入侵东海陆架途径包括近岸黑潮底层分支和远岸 黑潮底层分支两条途径, 分别沿 $60 \mathrm{~m}$ 等深线入侵至钱 塘江口和沿 $100 \mathrm{~m}$ 等深线影响东海陆架外侧, 图 $9 \mathrm{a}$ 很好 的印证了该结论. 图9b显示, 以盐度和温度作为计算 参数得出的黑潮入侵途径和范围与以 $\mathrm{Ba}$ 作为计算参 数得出的结果相似, 黑潮水占比 $95 \%$ 以上的位置位于

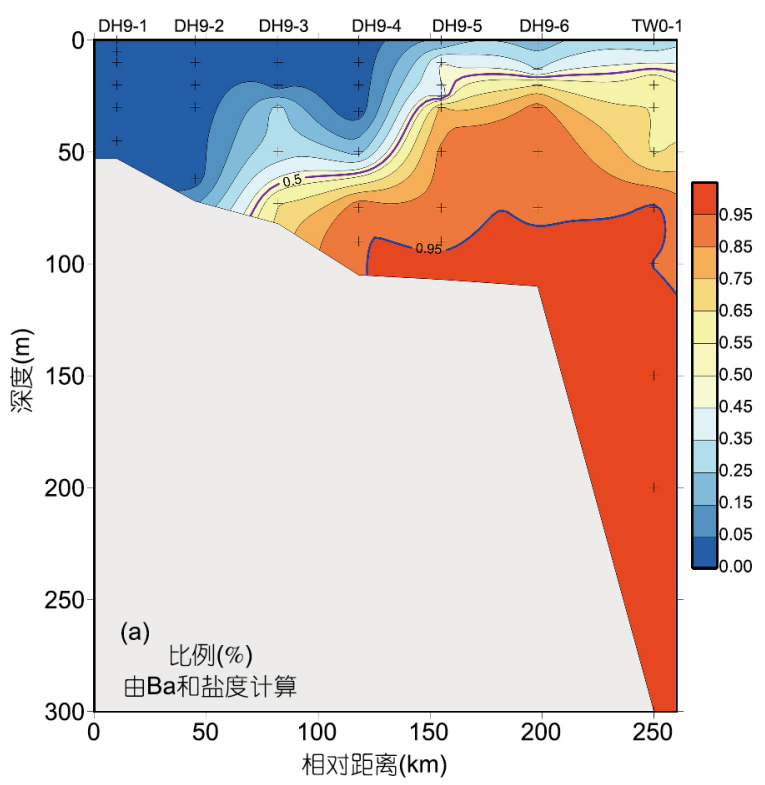

$100 \mathrm{~m}$ 等深线以深处, 而在陆架中部向北至钱塘江口出 现黑潮水的占比高值. 两组参数计算结果显示, 各站 位黑潮水所占比例虽有所差别, 但相差不大, 见两组 参数计算结果相关关系图. 这些支持了以 $\mathrm{Ba}$ 作为参数 得出的研究结果.

影响DH9断面的水团主要为黑潮次表层水、台湾 海峡水、中国近岸水这三个端元. 采用式 2 计算黑潮 水对该断面的入侵程度. 黑潮水在各站位所占比例见 图10. 由图 $10 \mathrm{a}$ 可以看出, 当以 $\mathrm{Ba}$ 和盐度作为计算参数 时，黑潮次表层水从陆架坡折处沿底部向上爬升，至

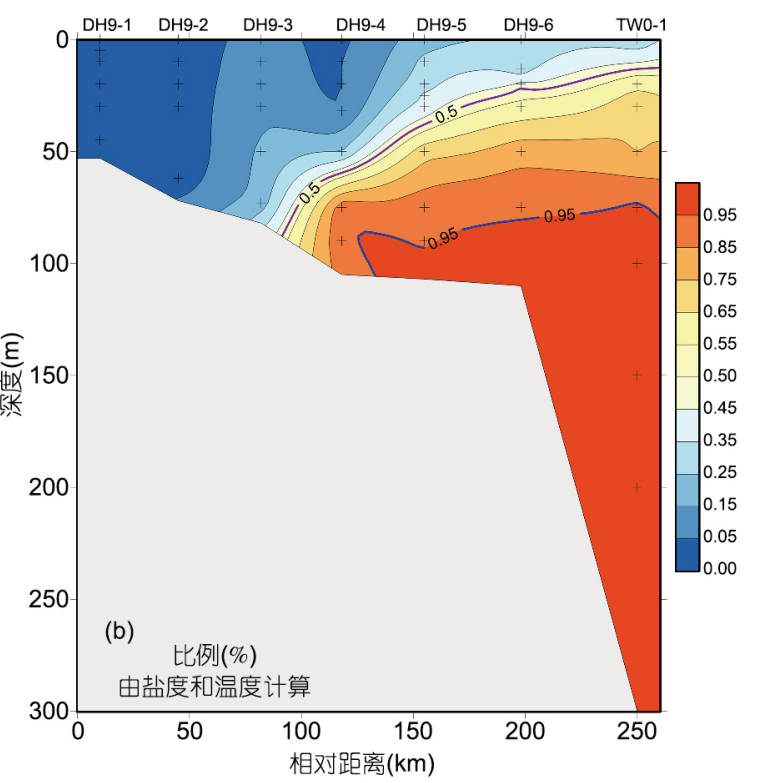

图 10 DH9断面黑潮水所占比例 
$122^{\circ} \mathrm{E}$ 左右(DH9-5站位)底部, 黑潮水仍能够占到 $95 \%$ 的比例. 垂直方向上, 越向上黑潮水所占比例越小, 陆 架外侧站位受黑潮次表层水的影响范围更大, 黑潮水 占 50\%比例位置可延伸至外侧TW0-1站位表层, 而内 侧靠近大陆的站位则只限于陆架中部位置底层. DH9 断面与中日黑潮合作调查研究期间IS断面位置相似, 林葵等(1995)的研究指出, 台湾东北IS断面处黑潮与 陆架水之间的交换表现为黑潮水从底向西插入陆架, 陆架水则从表层和次表层向东插入黑潮区, 春夏之时 黑潮水可到达 $122^{\circ} \mathrm{E}$ 左右的位置, 这与本文用钡指示 黑潮入侵东海的研究结果相一致. 图 $10 \mathrm{~b}$ 是单纯以盐 度和温度作为指示因子估算得出的黑潮对DH9断面的 入侵范围和程度, 与图10a中 Ba作为黑潮入侵东海指 示指标结果吻合. 两组参数计算结果相关关系见图 11.

以端元模式计算黑潮水在相应点位所占比例, 其 不确定性主要取决于各端元参数值的误差(见表 3 )及 各点位实测值误差. 根据误差传递原理, 分别计算以 $\mathrm{Ba}$ 和盐度作为参数时与以温度和盐度作为参数时各 点位黑潮水占比的总误差. 结果表明, 以 $\mathrm{Ba}$ 和盐度 作为计算参数时各点位黑潮水占比的总误差范围为 $2.8 \sim 10.3 \%$, 以温度和盐度作为计算参数时各点位黑潮 水占比的总误差范围为 1.7 6.0\%.

由上述分析可知, 以 $\mathrm{Ba}$ 作为指示指标获得的黑潮 入侵东海结果可有效揭示黑潮水运移的趋势, 海水溶 解 $\mathrm{Ba}$ 的地球化学特性符合端元模式计算参数应具备 的特点(Tomczak, 1981), 一是其化学行为较为保守, 二 是其与盐度、温度参数的变化是独立的, 不随二者的 变化而变化. 并且相对于海水混合过程, 对东海陆架 区海水而言, 各端元间较大的浓度差别使 $\mathrm{Ba}$ 受生物过

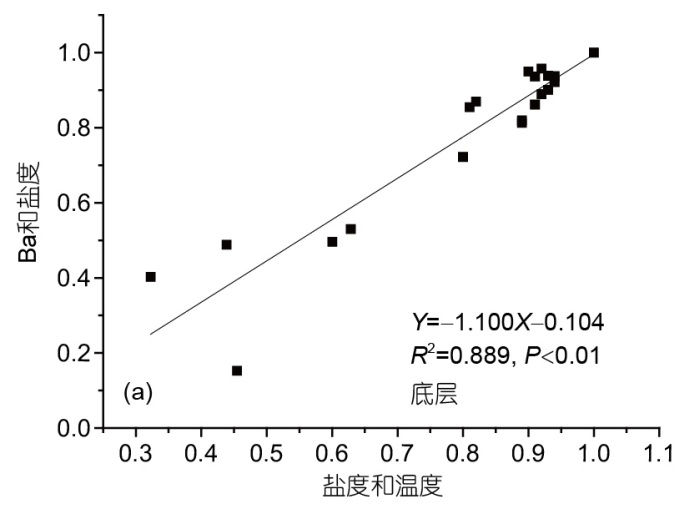

程影响的程度可以忽略. 因此, Ba成为指示黑潮入侵 东海的有效指标, 同时也为海洋水团研究中涉及四个 及更多水团定量混合计算提供温度、盐度之外的另 一有效参数.

\section{4 结论}

海水溶解钡 $(\mathrm{Ba})$ 在黑潮主体浓度从表层至深层逐 渐增大, 浓度范围为4.91 19.2 $\mu \mathrm{g} \mathrm{L}^{-1}$. 东海海水中溶解 $\mathrm{Ba}$ 的浓度同时受到黑潮水、陆源河流输入及台湾海 峡水的相互作用, 在不同水层上呈现出不同的特点. 表层海水Ba浓度以近岸海域为最高, 向外海逐渐降低, 底层则为近岸和外海海域较高, 中间海域出现低值.

黑潮在 5 10月间向东海的 Ba输入通量共计为 $2.19 \times 10^{8} \mathrm{~kg}$, 各层水中以次表层水的输入通量为最 大. 东海水通过陆架边缘向黑潮输送的 $\mathrm{Ba}$ 的通量为 $0.82 \times 10^{8} \mathrm{~kg} /$ 半年.

调查海域溶解 $\mathrm{Ba}$ 的地球化学特征和以 $\mathrm{Ba}$ 作为指 示指标定量估算结果表明, 黑潮通过在台湾东北部的 涌升而入侵东海陆架; 黑潮表层水受台湾海峡北向出 水和黑潮次表层水涌升的影响, 被限定在东海陆架东 南部, 对本次调查站位产生影响很小; 而黑潮次表层 水沿陆架底层爬升, 沿陆架中部向西北方向入侵, 至 钱塘江口附近海域黑潮水占比仍达到 $65 \%$ 左右. 黑潮 水占比 $95 \%$ 以上的位置位于东海陆架外侧 $100 \mathrm{~m}$ 等深 线以深处. 黑潮次表层水在台湾东北部DH9断面处沿 陆架破折向西从底部侵入陆架, 黑潮水占比 $95 \%$ 的位 置可至东经 $122^{\circ}$ 左右, 垂直向上黑潮水所占比例逐渐 减小. 研究结果显示, 海水溶解Ba能够很好的反映黑 潮入侵东海规律, 是指示黑潮入侵东海的有效指标,

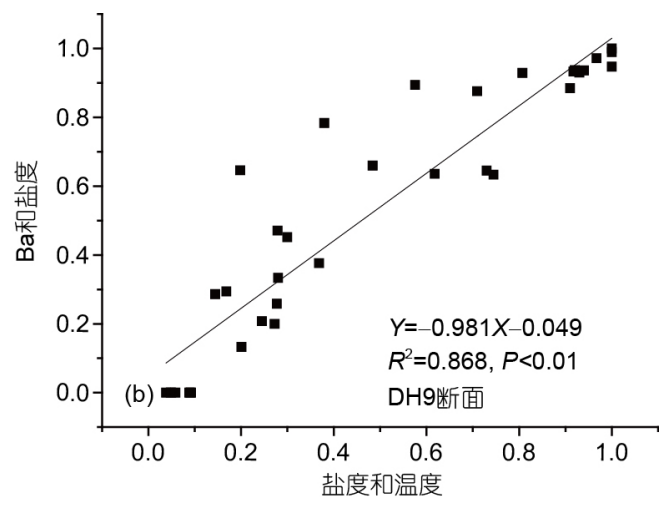

图 11 黑潮水占比两组参数计算结果相关关系 
也成为海洋多水团混合定量研究中温度、盐度之外 的另一有效参数.

\section{参考文献}

郭景松, 胡䈗敏, 袁业立. 2005. 利用卫星高度计资料对台湾海峡流 量变化的诊断分析. 海洋科学进展, 23: 20-26

林葵, 陈则实, 郭炳火, 汤艈祥. 1995. 东海黑潮水与陆架水的季节 性输运和交换. 黄渤海海洋, 13: 1-8

刘晓辉, 陈大可, 董昌明, 何海伦. 2015. 利用拉格朗日方法研究台 湾东北黑潮路径变化. 中国科学: 地球科学, 45: 1923-1936

卢汐, 宋金明, 袁华茂, 李宁, 李学刚, 段丽琴, 曲宝晓. 2016. 黑潮主 流径海域海水中的无机碳及其对东海陆架区的影响. 海洋与湖 沼, 2016, 1: 16-28

中华人民共和国水利部. 2013. 中国河流泥沙公报. 北京: 中国水 利水电出版社. 4

Atkinson L P. 2010. Western boundary currents. In: Carbon and Nutrient Fluxes in Continental Margins. Berlin: Springer-Verlag. 121-169

Bruland K W. 1983. Trace elements in sea water. In: Riley J, Chester R, eds. Chemical Oceanography. London: Academic Press. 8: 157-220

Cao Z M, Siebert C, Hathorne E C, Dai M H, Frank M. 2016. Constraining the oceanic barium cycle with stable barium isotopes. Earth Planet Sci Lett, 434: 1-9

Cardinal D, Savoye N, Trull T W, André L, Kopczynska E E, Dehairs F. 2005. Variations of carbon remineralisation in the Southern Ocean illustrated by the Baxs proxy. Deep-Sea Res Part I-Oceanogr Res Pap, 52: $355-370$

Chen C T A. 1996. The Kuroshio intermediate water is the major source of nutrients on the East China Sea continental shelf. Oceanol Acta, 19: $523-527$

Chen C T A. 1998. Response to Liu's comments on "The Kuroshio intermediate water is the major source of nutrients on the East China Sea continental shelf" by Chen (1996). Oceanol Acta, 21: 713-716

Chen C T A. 2009. Chemical and physical fronts in the Bohai, Yellow and East China seas. J Mar Syst, 78: 394-410

Chen C T A, Ruo R, Paid S C, Liu C T, Wong G T F. 1995. Exchange of water masses between the East China Sea and the Kuroshio off northeastern Taiwan. Cont Shelf Res, 15: 19-39

Chen C T A, Wang S L. 1999. Carbon, alkalinity and nutrient budgets on the East China Sea continental shelf. J Geophys Res, 104: 20675-20686

Chen C T A, Wang S L, Chou W C, Sheu D D. 2006. Carbonate chemistry and projected future changes in $\mathrm{pH}$ and $\mathrm{CaCO}_{3}$ saturation state of the South China Sea. Mar Chem, 101: 277-305

Dehairs F, Chesselet R, Jedwab J. 1980. Discrete suspended particles of barite and the barium cycle in the open ocean. Earth Planet Sci Lett,
49: $528-550$

Falkner K K, Mac Donald R W, Carmack E C, Weingartner T. 1994. The potential of barium as a tracer of Arctic water masses. In: Johannessen O M, Muench R D, Overland J E, eds. The Polar Oceans and Their Role in Shaping the Global Environment. Washington D C: American Geophysical Union. 63-76

Fukudome K I, Yoon J H, Ostrovskii A, Takikawa T, Han I S. 2010. Seasonal volume transport variation in the Tsushima Warm Current through the Tsushima Straits from 10 years of ADCP observations. J Oceanogr, 66: 539-551

Ganeshram R S, François R, Commeau J, Brown-Leger S L. 2003. An experimental investigation of barite formation in seawater. Geochim Cosmochim Acta, 67: 2599-2605

Guan B X, Fang G H. 2006. Winter counter-wind currents off the southeastern China coast: A review. J Oceanogr, 62: 1-24

Guo B H, Hu X M, Xiong X J, Ge R F. 2003. Study on interaction between the coastal water, shelf water and Kuroshio water in the Huanghai Sea and East China Sea. Acta Oceanol Sin, 3: 351-367

Guo X Y, Zhu X H, Wu Q S, Huang D J. 2012. The Kuroshio nutrient stream and its temporal variation in the East China Sea. J Geophys Res, 117: C01026

Hong G H, Zhang J, Chung C S. 2002. Impact of Interface Exchange on the Biogeochemical processes of the Yellow and East China seas. Seoul: Bumshin Press. 85-499

Hoppema M, Dehairs F, Navez J, Monnin C, Jeandel C, Fahrbach E, de Baar H J W. 2010. Distribution of barium in the Weddell Gyre: Impact of circulation and biogeochemical processes. Mar Chem, 122: $118-129$

Horner T J, Kinsley C W, Nielsen S G. 2015. Barium-isotopic fractionation in seawater mediated by barite cycling and oceanic circulation. Earth Planet Sci Lett, 430: 511-522

Hsueh Y. 2000. The Kuroshio in the East China Sea. J Mar Syst, 24: $131-139$

Jeandel C, Dupré B, Lebaron G, Monnin C, Minster J F. 1996. Longitudinal distributions of dissolved barium, silica and alkalinity in the western and southern Indian Ocean. Deep-Sea Res Part I-Oceanogr Res Pap, 43: 1-31

Li H M, Shi X Y, Wang H, Han X R. 2014. An estimation of nutrient fluxes to the East China Sea continental shelf from the Taiwan Strait and Kuroshio subsurface waters in summer. Acta Oceanol Sin, 33: $1-10$

Lin I T, Wang C H, You C F, Lin S, Huang K F, Chen Y G. 2010. Deep submarine groundwater discharge indicated by tracers of oxygen, strontium isotopes and barium content in the Pingtung coastal zone, southern Taiwan. Mar Chem, 122: 51-58

Miller A R. 1950. A study ofmixing processes over the edge of thecon- 
tinental shelf. J Mar Res, 9: 145-160

Monnin C A. 1999. A thermodynamic model for the solubility of barite and celestite in electrolyte solutions and seawater to $200^{\circ} \mathrm{C}$ and to 1 kbar. Chem Geol, 153: 187-209

Monnin C, Cividini D. 2006. The saturation state of the world's ocean with respect to $(\mathrm{Ba}, \mathrm{Sr}) \mathrm{SO}_{4}$ solid solutions. Geochim Cosmochim Acta, 70: 3290-3298

Nozaki Y, Yamamoto Y, Manaka T, Amakawa H, Snidvongs A. 2001. Dissolved barium and radium isotopes in the Chao Phraya River estuarine mixing zone in Thailand. Cont Shelf Res, 21: 1435-1448

Paytan A, Griffith E M. 2007. Marine barite: Recorder of variations in ocean export productivity. Deep-Sea Res Part II-Top Stud Oceanogr, 54: 687-705

Qi J F, Yin B S, Zhang Q L, Yang D Z, Xu Z H. 2014. Analysis of seasonal variation of water masses in East China Sea. Chin J Ocean Limnol, 32: 958-971

Roeske T, Bauch D, Rutgers V.D. Loeff M, Rabe B. 2012. Utility of dissolved barium in distinguishing North American from Eurasian runoff in the Arctic Ocean. Mar Chem, 132-133: 1-14

Singh S P, Singh S K, Bhushan R. 2013. Internal cycling of dissolved barium in water column of the Bay of Bengal. Mar Chem, 154: 12-23 Sheu D D, Lee W Y, Wang C H, Wei C L, Chen C T A, Cherng C, Huang M H. 1996. Depth distribution of $\delta^{13} \mathrm{C}$ of dissolved $\Sigma \mathrm{CO}_{2}$ in seawater off eastern Taiwan: Effects of the Kuroshio current and its associated upwelling phenomenon. Cont Shelf Res, 16: 1609-1619

Song J M. 2010. Biogeochemical Processes of Biogenic Elements in China Marginal Seas. Berlin: Springer-Verlag. 39
Tomczak M. 1981. A multi-parameter extension of temperature/salinity diagram techniques for the analysis of non-isopycnal mixing. Prog Oceanogr, 10: 147-171

Wong G T F, Chao S Y, Li Y H, Shiah F K. 2000. The Kuroshio edge exchange processes (KEEP) study-An introduction to hypotheses and highlights. Cont Shelf Res, 20: 335-347

Wu B, Zhao D Y, Jia H Y, Zhang Y, Zhang X X, Cheng S P. 2009. Preliminary risk assessment of trace metal pollution in surface water from Yangtze River in Nanjing Section, China. Bull Environ Contam Toxicol, 82: 405-409

Yang D Z, Yin B S, Liu Z L, Feng X R. 2011. Numerical study of the ocean circulation on the East China Sea shelf and a Kuroshio bottom branch northeast of Taiwan in summer. J Geophys Res, 116: C05015

Yang D Z, Yin B S, Liu Z L, Bai T, Qi J F, Chen H Y. 2012.Numerical study on the pattern and origins of Kuroshio branches in the bottom water of southern East China Sea in summer. J Geophys Res, 117: $1-16$

Zhang J, Liu S M, Ren J L, Wu Y, Zhang G L. 2007. Nutrient gradients from the eutrophic Changjiang (Yangtze River) Estuary to the oligotrophic Kuroshio waters and re-evaluation of budgets for the East China Sea Shelf. Prog Oceanogr, 74: 449-478

Zhang L, Liu Z, Zhang J, Hong G H, Park Y, Zhang H F. 2007. Reevaluation of mixing among multiple water masses in the shelf: An example from the East China Sea. Cont Shelf Res, 27: 1969-1979

Zhang Q H, Qu Y Y, Li J K, Yin X Q. 2015. A theoretical model for the intrusion of the Kuroshio across the continental shelf of East China Sea. Sci China Earth Sci, 58: 2289-2295 